\title{
How and why does discretionary food consumption change when we promote fruit and vegetables? Results from the ShopSmart randomised controlled trial
}

\author{
Rachelle S Opie, Sarah A McNaughton, David Crawford, Gavin Abbott and Kylie Ball* \\ Institute for Physical Activity and Nutrition (IPAN), School of Exercise and Nutrition Sciences, Deakin University, \\ Geelong, VIC 3125, Australia
}

Submitted 2 October 2018: Final revision received 23 May 2019: Accepted 24 June 2019: First published online 1 October 2019

\begin{abstract}
Objective: The present study aimed to identify whether discretionary food consumption declined in an intervention focused primarily on promoting fruit and vegetable consumption. We also aimed to identify potential mediators explaining intervention effects on discretionary food consumption.

Design: Secondary analysis of data from the ShopSmart study, a randomised controlled trial involving a 6-month intervention promoting fruit and vegetable consumption. Linear regression models examined intervention effects on discretionary food consumption at intervention completion (T2). A half-longitudinal mediator analyses was performed to examine the potential mediating effect of personal and environmental factors on the association between the intervention effects and discretionary food consumption. Indirect (mediated) effects were tested by the product of coefficients method with bootstrapped SE using Andrew Hayes' PROCESS macro for SPSS.

Setting: Women were recruited via the Coles FlyBuys loyalty card database in socio-economically disadvantaged suburbs of Melbourne, Australia.

Participants: Analyses included 225 women (116 intervention and 109 control). Results: Compared with controls, intervention participants consumed fewer discretionary foods at T2, after adjusting for key confounders $(B=-0 \cdot 194$, $95 \%$ CI $-0.378,-0.010$ servings $/ \mathrm{d} ; P=0.039)$. While some mediators were associated with the outcome (taste, outcome expectancies, self-efficacy, time constraints), there was no evidence that they mediated intervention effects. Conclusions: The study demonstrated that a behavioural intervention promoting fruit and vegetable consumption among socio-economically disadvantaged participants was effective in reducing discretionary food intake. Although specific mediators were not identified, researchers should continue searching for mechanisms by which interventions have an effect to guide future programme design.
\end{abstract}

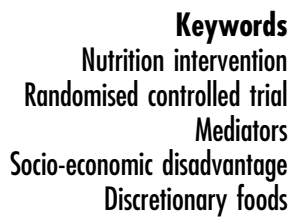

Poor diet quality is one of the leading risk factors for non-communicable diseases such as CVD, cancer, chronic respiratory disease and diabetes, which kill 41 million people globally each year ${ }^{(1)}$. Socio-economic position is closely linked with non-communicable diseases; specifically, in high-income countries, non-communicable disease rates are higher in disadvantaged and marginalised people than in groups of higher socio-economic position ${ }^{(2)}$. Socially disadvantaged people are more likely to become ill and die prematurely than people of higher social positions, in part because they are at greater risk of being exposed to unhealthy behaviours such as dietary practices that are not aligned with recommendations ${ }^{(1)}$. Despite the convincing evidence to date regarding the health benefits associated with healthy eating, alarmingly, the average diet quality of the Western population continues to remain poor $^{(3,4)}$. In fact, in Australia approximately $35 \%$ of energy consumption comes from discretionary food intake ${ }^{(5)}$ and US data indicate that $86 \%$ of the population consumes more than the recommended limit of discretionary choices ${ }^{(4)}$. Unhealthy discretionary items include sweet biscuits, cakes, confectionary, chocolate, ice cream and other ice confections, processed meats and sausages, pastries, pies, fried foods, potato chips, 
crisps, fatty and/or salty snack foods, sugar-sweetened soft drinks and cordials, and alcoholic drinks ${ }^{(6)}$.

A range of interventions have been shown to successfully promote fruit and vegetable consumption ${ }^{(7)}$. For example, trials targeted at adults living on a low income have reported effects ranging from approximately $+0 \cdot 42$ to $+1 \cdot 1$ servings of fruits and vegetables daily ${ }^{(8-12)}$. However, those studies have not reported whether such programmes concomitantly reduce discretionary food consumption, in the absence of an explicit focus on restricting such foods ${ }^{(7)}$. At best, they may simply aim to reduce kilojoules from fat ${ }^{(8,10)}$. For example, two interventions ${ }^{(8,10)}$ aimed at promoting fruit and vegetable consumption also focused on reducing fat intake, primarily through encouraging recipe modification and choosing lower-fat versions of foods. While neither study reported on discretionary food intake specifically, both found positive intervention effects on both increased fruit and vegetable consumption and reduced intake of kilojoules from fat.

Of relevance, programmes focusing on weight loss as an outcome commonly emphasise energy restriction. While these may achieve weight loss (or minimise weight gain) during the treatment period, this is commonly followed by regain of some, if not all, of the lost weight ${ }^{(13)}$. Some studies have even shown that one- to two-thirds of dieters regain more weight than they lost on their diets ${ }^{(14)}$. One possible reason is that too great an emphasis is placed on outcome motivators (e.g. weight loss), with insufficient attention to process motivators which are key to influencing behaviour ${ }^{(13,15)}$. Process motivators are the factors that elicit and sustain attention to and persistence in an activity (e.g. increase intrinsic motivation for participating in the process of behaviour change such as fun, taste, control, social interaction and pride $)^{(13)}$. To achieve behaviour change, it has been suggested that the activities required for the behaviour change process are rewarding ${ }^{(13)}$. Hence, programmes that promote consumption of healthy foods by encouraging self-efficacy (e.g. label reading, meal planning, cooking, budgeting, etc.), meal enjoyment, social interaction and goal setting, while drawing minimal attention to restricting unhealthy foods, are a potentially promising approach for achieving success. Such an approach is similar to that of the theory-based stealth interventions, which are designed to make the process of behaviour change rewarding, easy and desirable rather than a sacrifice or burden, as 'diets' are often perceived to be ${ }^{(13)}$.

Potential mechanisms by which programmes that promote healthy food consumption may result in subsequent decreases in (and displacement of) unhealthy foods include increased preferences for healthier foods ${ }^{(16,17)}$; greater skills and confidence in food preparation and cooking; and/or reduced environmental constraints related to procuring, preparing and eating nutritious produce ${ }^{(18)}$. However, few studies have examined these proposed mechanisms and the potential to influence changes in discretionary food consumption indirectly through nutrition promotion ${ }^{(13)}$.
The aim of the present study was to identify whether discretionary food consumption declined in an intervention whose primary focus was to promote fruit and vegetable consumption. Of note, in the original study ('ShopSmart') vegetable consumption increased among socio-economically disadvantaged women ${ }^{(19)}$. In the current secondary analysis we also aimed to identify potential mechanisms (mediators) explaining any intervention effects on discretionary food consumption, drawing on past research of determinants for food choice and eating behaviours informed by social cognitive theory ${ }^{(15,20)}$ to guide mediator selection. Social cognitive theory ${ }^{(15,20)}$ posits that behaviours are learned and this learning is influenced by the interaction of personal and environmental, as well as behavioural factors. In the present study we focus on both personal factors (self-efficacy, taste preferences and outcome expectancies) and environmental factors (time, cost and availability constraints), given their established links with eating behaviours ${ }^{(15,20)}$. Exploring the mechanisms that drive food choice provides an opportunity to better understand the reasons for intervention successes and failures, with the potential to design programmes that achieve positive food consumption behaviours.

\section{Methods}

The ShopSmart study was a randomised controlled trial targeted at women of low socio-economic position, aimed at testing the effectiveness of a skill-building intervention promoting fruit and vegetable consumption (www.isrctn.com, ISRCTN48771770) ${ }^{(19,21)}$. The findings presented here are additional, opportunistic analyses of the ShopSmart intervention data using secondary trial outcomes (mediators) and an additional trial outcome (discretionary food intake). Women were the focus, since they are primarily responsible for food purchasing and preparation in households ${ }^{(22)}$. The trial comprised a 3-month retrospective baseline data collection phase (involving retrieval of data for a 3-month retrospective period (after participants registered and consented to the study, but before the intervention began)), followed by a 6-month intervention period and a further 6-month no-intervention follow-up period. The intervention development was guided by social cognitive theory ${ }^{(15)}$ to ensure a strong theoretical, empirical and practical foundation.

Women were recruited via the Coles FlyBuys loyalty card database from one of two catchment areas (randomly selected disadvantaged neighbourhoods serviced by a Coles store and within $25 \mathrm{~km}$ of the main research site; see Ball et al. for further details $\left.{ }^{(19,21)}\right)$. Two hundred and forty-eight women returned baseline surveys and were randomly assigned to either the behavioural intervention ( $n$ 124) or the control ( $n$ 124) condition by using a computer-generated block randomisation sequence, produced and implemented by an independent statistician, that involved blocks of 2 and 4 in varying combinations. 


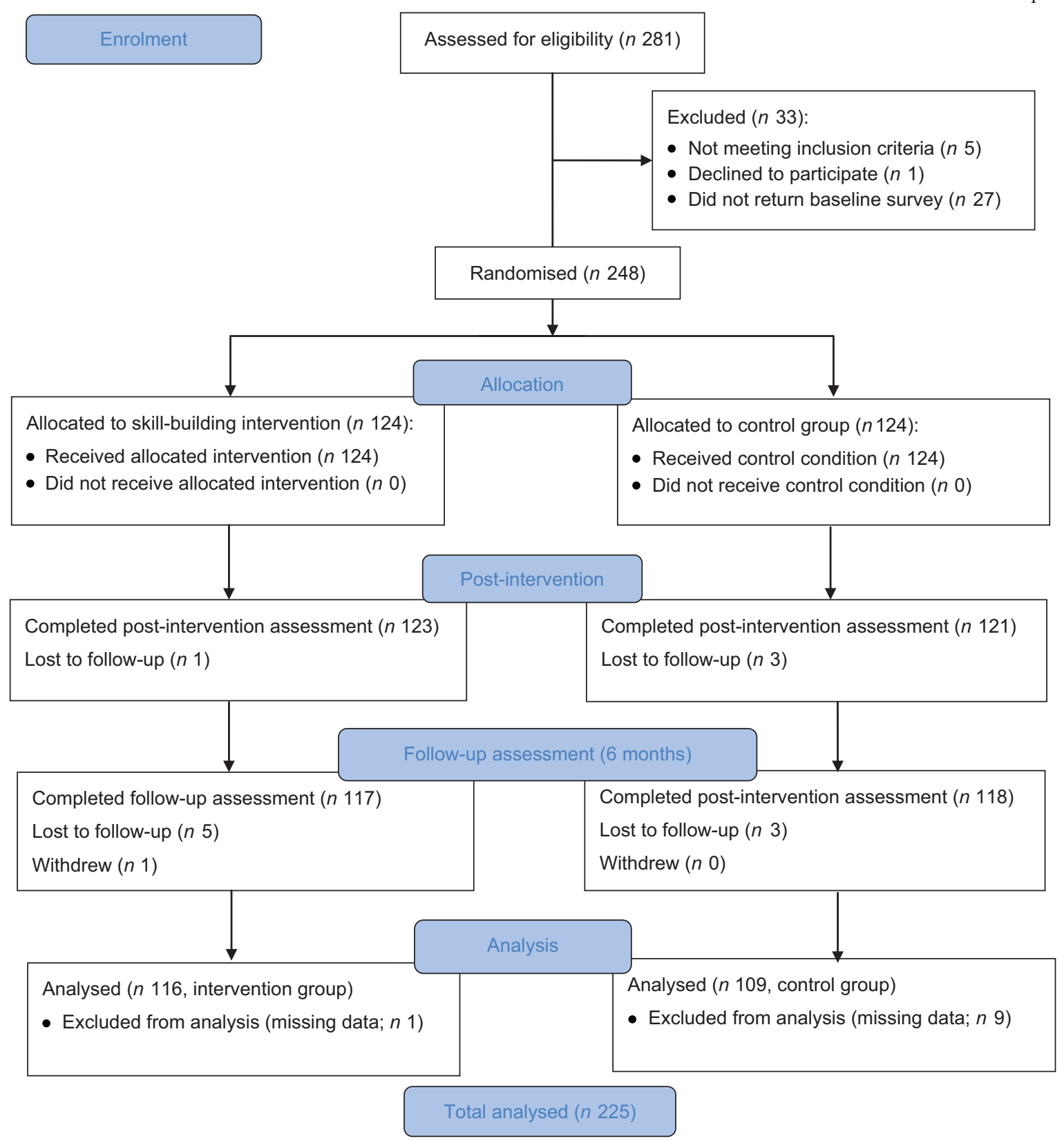

Fig. 1 (colour online) ShopSmart participant recruitment and flow through the study

Only women with complete data for all reported variables (including survey questionnaires regarding food shopping or dietary behaviours) at baseline (time T1) and intervention completion (time T2) were included in these analyses. Hence, the complete case sample included 225 women (116 intervention and 109 control). See Fig. 1 for ShopSmart participant recruitment and flow through the study.

\section{Intervention}

Women in the intervention arm received a set of eight educational and skill-building newsletters and behaviour change resource packages (sent fortnightly for the first 2 months and monthly for the remaining 4 months of the intervention). They were also invited to take part in a dietitian-led supermarket tour, which provided practical experience and skills in selecting fresh produce, as well as label reading to identify healthier food items. Resources were informed by social cognitive theory ${ }^{(15)}$ and designed to specifically address disadvantaged women's needs. They focused primarily on affordability and nutrition-related attitudes and skills. ShopSmart intervention details are described in full elsewhere ${ }^{(21)}$.

\section{Data collection and outcome measures}

Diet was measured using an FFQ composed of items assessing usual frequency of intake, previously developed 
for use with Australian adults in the 1995 National Nutrition Survey ${ }^{(23)}$ and other Australian population-based surveys ${ }^{(24,25)}$. Discretionary food consumption was assessed by self-reported mailed surveys completed pre-intervention (T1), at intervention completion (T2) and at 6 months post-intervention (T3). Total discretionary foods was made up of the sum of nine individual items (i.e. potato crisps, hot chips, chocolates, cakes, pies, fast food, pizza, alcohol and soft drink). Respondents were asked: 'About how often have you eaten the following: a. potato crisps (or salty snack foods), b. hot chips (or roast potatoes, potato wedges), c. chocolate (or lollies), d. cakes (or doughnuts, sweet biscuits), e. pies (or pastries, sausage rolls), f. fast foods, g. pizza?', with nine response options ranging from 'never or less than once/month' to ' 6 or more times/day'. As these questions did not include portion size, each occasion of eating was assumed to represent a single serving, equivalent to a single serving of discretionary items based on the Australian Dietary Guidelines $^{(6)}$. For example, a single serving of discretionary foods that provides approximately $600 \mathrm{~kJ}$ is: 2 scoops of regular ice cream, or 2 slices of processed meat, or $30 \mathrm{~g}$ of salty crackers, or $40 \mathrm{~g}$ of plain cake, or $25 \mathrm{~g}$ of chocolate, or $1 / 3$ of a commercial meat pie, or 12 hot $\operatorname{chips}^{(6)}$. Alcohol consumption was assessed using a combination of two questions, 'On average how often did you drink beer, wine and/or spirits?' and 'On days when you were drinking alcohol, about how many glasses of beer, wine and/or spirits altogether did you usually drink?', which allowed for calculation of the number of glasses of alcohol per day. Based on the Australian Dietary Guidelines, two standard drinks was equivalent to a single discretionary serving (e.g. approximately $600 \mathrm{~kJ})^{(26)}$. Finally, for soft drink consumption (e.g. regular (sugar-sweetened) carbonated soft drink), respondents were asked 'About how much full-calorie soft drink do you usually drink each day?', with ten response options ranging from 'I don't drink soft drink' to ' 6 or more serves/day'. One can of full-calorie soft drink $(375 \mathrm{ml})$ was equivalent to a single discretionary serving ${ }^{(6)}$.

Sociodemographic characteristics assessed included age, country of birth, relationship status, highest attained level of education, smoking status, whether they had children and BMI. These measures were collected in self-reported surveys completed at T1. The control group completed assessments only, and at the conclusion of the study were offered all of the printed intervention materials.

\section{Mediator selection}

The eleven ShopSmart survey questions, and response options, utilised for assessing food shopping and dietary behaviours that allowed for mediator analysis are provided in Table 1. The mediators selected were constructs, represented by the items described in Table 1, selected based on past research of determinants of food choice and eating behaviours $^{(27,28)}$, which align with social cognitive theory ${ }^{(15)}$. They were categorised as personal or environmental constructs or both, consistent with theory and past research ${ }^{(29)}$.

\section{Statistical analysis}

Descriptive analyses were performed on baseline characteristics of the original ShopSmart cohort ( $n$ 248) and the total eligible sub-sample ( $n$ 225), including the intervention ( $n$ 116) and control groups ( $n$ 109). Wilcoxon-signed rank tests were used to explore the changes in dietary intake (servings per day of discretionary items) from baseline to post-intervention completion (6 months post-baseline) for the intervention and control group. These analyses were performed to establish whether the ShopSmart

Table 1 ShopSmart survey questions, with their proposed constructs and response options, that were examined as potential mediators

\begin{tabular}{|c|c|c|c|}
\hline Survey question & Relevant construct ${ }^{(15,37,39)}$ & $\begin{array}{l}\text { No. of response } \\
\text { options }\end{array}$ & Response options \\
\hline $\begin{array}{l}\text { 'I like the taste of full-calorie soft drinks too much } \\
\text { to cut down on drinking these' }\end{array}$ & Personal: food tastes/preferences & 3 & 'Agree' to 'disagree' \\
\hline 'I like to drink water’ & Personal: food tastes/preferences & 3 & 'Agree' to 'disagree' \\
\hline $\begin{array}{l}\text { 'I feel confident that I can eat fruit or vegetables } \\
\text { as snacks' }\end{array}$ & Personal: self-efficacy & 3 & 'Agree' to 'disagree' \\
\hline $\begin{array}{l}\text { 'When food shopping how much do you consider } \\
\text { your own health' }\end{array}$ & $\begin{array}{l}\text { Personal: outcome expectancies } \\
\text { (health) }\end{array}$ & 4 & 'Not at all' to 'very much' \\
\hline $\begin{array}{l}\text { 'How confident do you feel about preparing } \\
\text { and cooking fruit and vegetables that you have } \\
\text { not cooked with before' }\end{array}$ & Personal: self-efficacy & 7 & $\begin{array}{l}\text { 'Extremely confident' to 'not } \\
\text { at all confident' }\end{array}$ \\
\hline $\begin{array}{l}\text { 'I feel that I have enough knowledge about how } \\
\text { to prepare/cook vegetables' }\end{array}$ & Personal: self-efficacy & 3 & 'Agree' to 'disagree' \\
\hline $\begin{array}{l}\text { 'I feel that vegetables are time-consuming to } \\
\text { prepare' }\end{array}$ & $\begin{array}{l}\text { Environmental/Personal: time } \\
\text { constraints }\end{array}$ & 3 & 'Agree' to 'disagree' \\
\hline 'I feel that fruit is too expensive' & $\begin{array}{l}\text { Environmental/Personal: cost/ } \\
\text { affordability }\end{array}$ & 3 & 'Agree' to 'disagree' \\
\hline 'I feel that vegetables are too expensive' & $\begin{array}{l}\text { Environmental/Personal: cost/ } \\
\text { affordability }\end{array}$ & 3 & 'Agree' to 'disagree' \\
\hline 'I feel that fruit is not always available' & Environmental: availability & 3 & 'Agree' to 'disagree' \\
\hline 'I feel that vegetables are not always available' & Environmental: availability & 3 & 'Agree' to 'disagree' \\
\hline
\end{tabular}




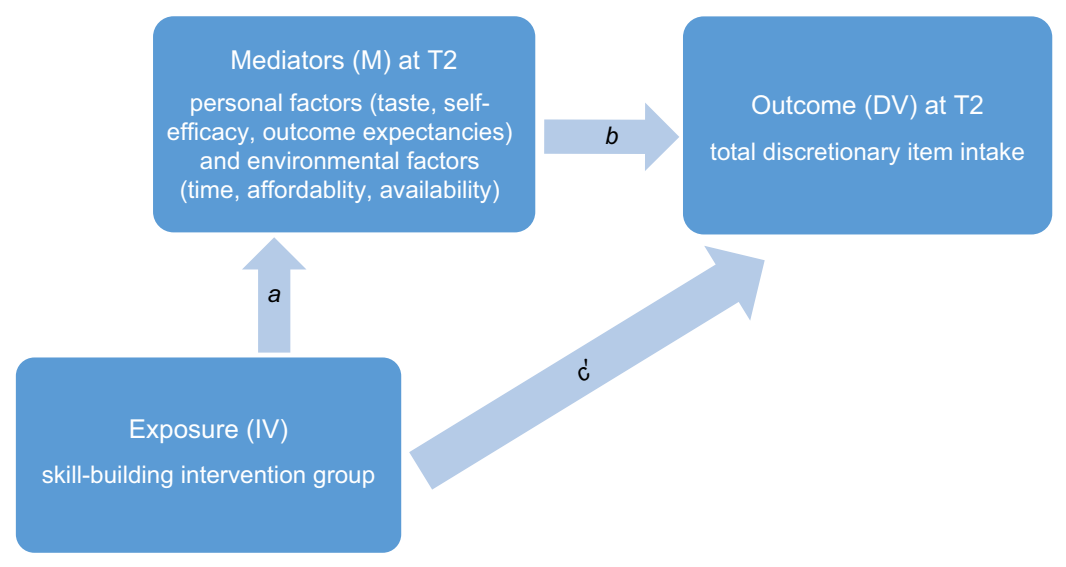

Fig. 2 (colour online) Mediator model for examining potential mediating effects of personal factors (at T2) of intervention effects and on total discretionary food consumption (at T2) in the ShopSmart randomised controlled trial (M, mediator; DV, dependent variable; IV, independent variable; T2, intervention completion, 6 months post-baseline)

programme (primarily aimed at promoting fruit and vegetable consumption) was associated with changes in the measure of total discretionary items and its sub-components (i.e. potato crisps, hot chips, chocolates, cakes, pies, fast food, pizza, alcohol and soft drink).

Linear regression models examined intervention effects on self-reported total discretionary food consumption at T2. Because of the skewed distribution of the dependent variable, $\log$ transformation was performed (log normal). When modelling a log-transformed outcome, regression coefficients and CI can be exponentiated (i.e. $\mathrm{e}^{b}$ ) and subsequently interpreted as proportional differences in the geometric mean (approximately the median) of the outcome. All of the models controlled for baseline levels of the outcome and for the following covariates (determined a priori): catchment area (one of two neighbourhoods), age (years), country of birth (Australia, other), relationship status (married/de facto, separated/divorced/widowed, never married), highest attained level of education (low (less than Year 12), medium (Year 12/trade/diploma), high (tertiary)), smoking status (never, former, current), children (yes, no) and BMI $\left(\mathrm{kg} / \mathrm{m}^{2}\right)$.

A half-longitudinal mediator analysis ${ }^{(30)}$ was performed to examine the potential mediating effects of personal and environmental factors (T2) on the association between the intervention effects and on total discretionary food consumption (T2). This analysis allowed for a better understanding of the explanatory pathways/mechanisms by which the intervention led to the dietary outcome. The half-longitudinal approach to mediation is typically used when there is no temporal separation between measurement of the mediator and the outcome variable ${ }^{(30)}$. Although we had three time points of data available, the half-longitudinal analysis was the preferred method (rather than a full longitudinal analysis) since the outcome of interest was discretionary food consumption at intervention completion (T2), rather than 6 months post-intervention (T3). Indirect (mediated) effects were tested by the product of coefficients method with bootstrapped sE using Andrew
Hayes' PROCESS macro for SPSS ${ }^{(31)}$. The proposed mediation model can be seen in Fig. 2, which includes the exposure/independent variable (IV) (skill-building intervention group), the mediators (M) and the outcome/dependent variable (DV) (discretionary food intake). As seen in Fig. 2, $a$ represents the relationship of IV to $\mathrm{M}$, and $b$ represents the relationship of $\mathrm{M}$ to DV adjusting for IV. There is a direct effect $\left(c^{\prime}\right)$ relating IV to DV adjusting for $M$, and a mediated effect where IV indirectly affects DV through M. Finally, the model controlled for the covariates listed above, as well as baseline levels of the mediators.

Statistical significance was set at $P<0.05$ (two-tailed) and all statistical analyses were conducted using the statistical software package IBM SPSS Statistics version 25 (2017).

\section{Results}

\section{Descriptive statistics}

Baseline characteristics of the Shopsmart cohort and the eligible sub-sample (total cohort, intervention and control groups) are displayed in Table 2.

From baseline to intervention completion among intervention group participants, noticeable improvements were observed for intakes of total discretionary foods and individual discretionary food items (potato crisps, chocolates and cakes; $P<0.05$ ). In contrast, as expected, no obvious improvements in any discretionary food were found among control group participants $(P>0.05)$, other than for cake $(P=0.001$; Table 3$)$.

\section{Linear regression analysis}

Linear regression analysis showed that compared with controls, intervention participants consumed fewer discretionary foods at intervention completion (T2; $B=-0 \cdot 194$, $95 \% \mathrm{CI}-0.378,-0.010$ servings/d; $P=0.039)$ after controlling for baseline levels of discretionary foods and covariates 
Table 2 Baseline characteristics of the original ShopSmart cohort and the eligible sub-sample (total cohort, intervention and control groups)

\begin{tabular}{|c|c|c|c|c|c|c|c|c|}
\hline & & & \multicolumn{6}{|c|}{ Eligible sub-sample } \\
\hline & \multicolumn{2}{|c|}{$\begin{array}{c}\text { Original } \\
\text { ShopSmart cohort } \\
(n 248)\end{array}$} & \multicolumn{2}{|c|}{$\begin{array}{l}\text { Total cohort } \\
\quad(n 225)\end{array}$} & \multicolumn{2}{|c|}{$\begin{array}{l}\text { Intervention group } \\
\quad(n 116)\end{array}$} & \multicolumn{2}{|c|}{$\begin{array}{l}\text { Control group } \\
\quad(n 109)\end{array}$} \\
\hline & Mean or \% & SD or $n$ & Mean or \% & SD or $n$ & Mean or \% & SD or $n$ & Mean or $\%$ & SD or $n$ \\
\hline Age (years), mean and SD & $43 \cdot 11$ & $10 \cdot 46$ & $43 \cdot 60$ & $10 \cdot 42$ & $43 \cdot 71$ & $10 \cdot 49$ & 43.48 & $10 \cdot 39$ \\
\hline \multicolumn{9}{|l|}{ Catchment area, $\%$ and $n$} \\
\hline Dandenong & $28 \cdot 6$ & 71 & $27 \cdot 1$ & 61 & $23 \cdot 3$ & 27 & $31 \cdot 2$ & 34 \\
\hline Broadmeadows & 71.4 & 177 & $72 \cdot 9$ & 164 & $76 \cdot 7$ & 89 & $68 \cdot 8$ & 75 \\
\hline $\begin{array}{l}\text { Born in Australia, \% and } n \\
\text { Marital status, } \% \text { and } n\end{array}$ & $69 \cdot 4$ & 172 & 69.8 & 157 & $69 \cdot 0$ & 80 & $70 \cdot 6$ & 77 \\
\hline Married/de facto & $57 \cdot 7$ & 143 & $58 \cdot 2$ & 131 & $56 \cdot 9$ & 66 & $59 \cdot 6$ & 65 \\
\hline Separated/divorced/widowed & $22 \cdot 2$ & 55 & $23 \cdot 1$ & 52 & $19 \cdot 8$ & 23 & $26 \cdot 6$ & 29 \\
\hline Never married & $20 \cdot 2$ & 50 & $18 \cdot 7$ & 42 & $23 \cdot 3$ & 27 & $13 \cdot 8$ & 15 \\
\hline \multicolumn{9}{|l|}{ Highest education level, $\%$ and $n$} \\
\hline Low (less than Year 12) & $32 \cdot 8$ & 81 & 32.4 & 73 & $36 \cdot 2$ & 42 & 28.4 & 31 \\
\hline Medium (Year 12/trade/diploma) & $53 \cdot 6$ & 133 & $54 \cdot 2$ & 122 & $56 \cdot 0$ & 65 & $52 \cdot 3$ & 57 \\
\hline High (tertiary) & $13 \cdot 8$ & 34 & $13 \cdot 3$ & 30 & $7 \cdot 8$ & 9 & $19 \cdot 3$ & 21 \\
\hline Children (yes), $\%$ and $n$ & $55 \cdot 2$ & 137 & $55 \cdot 7$ & 123 & $55 \cdot 2$ & 64 & $54 \cdot 1$ & 59 \\
\hline \multicolumn{9}{|l|}{ Smoking status, $\%$ and $n$} \\
\hline Never smoked & $52 \cdot 8$ & 131 & $52 \cdot 9$ & 119 & $56 \cdot 0$ & 65 & 49.5 & 54 \\
\hline Former smoker & $20 \cdot 6$ & 51 & $20 \cdot 9$ & 47 & $21 \cdot 6$ & 25 & $20 \cdot 2$ & 22 \\
\hline Current smoker & $26 \cdot 7$ & 66 & $26 \cdot 2$ & 59 & 22.4 & 26 & $30 \cdot 3$ & 33 \\
\hline BMI $\left(\mathrm{kg} / \mathrm{m}^{2}\right)$, mean and SD & $28 \cdot 64$ & $7 \cdot 75$ & $28 \cdot 77$ & 7.93 & $29 \cdot 18$ & $8 \cdot 47$ & $28 \cdot 24$ & $7 \cdot 33$ \\
\hline
\end{tabular}

Table 3 Change in discretionary item consumption (servings per day) from baseline (T1) to intervention completion (T2; 6 months postbaseline) for the intervention and control groups in the ShopSmart randomised controlled trial. Wilcoxon signed-rank tests performed

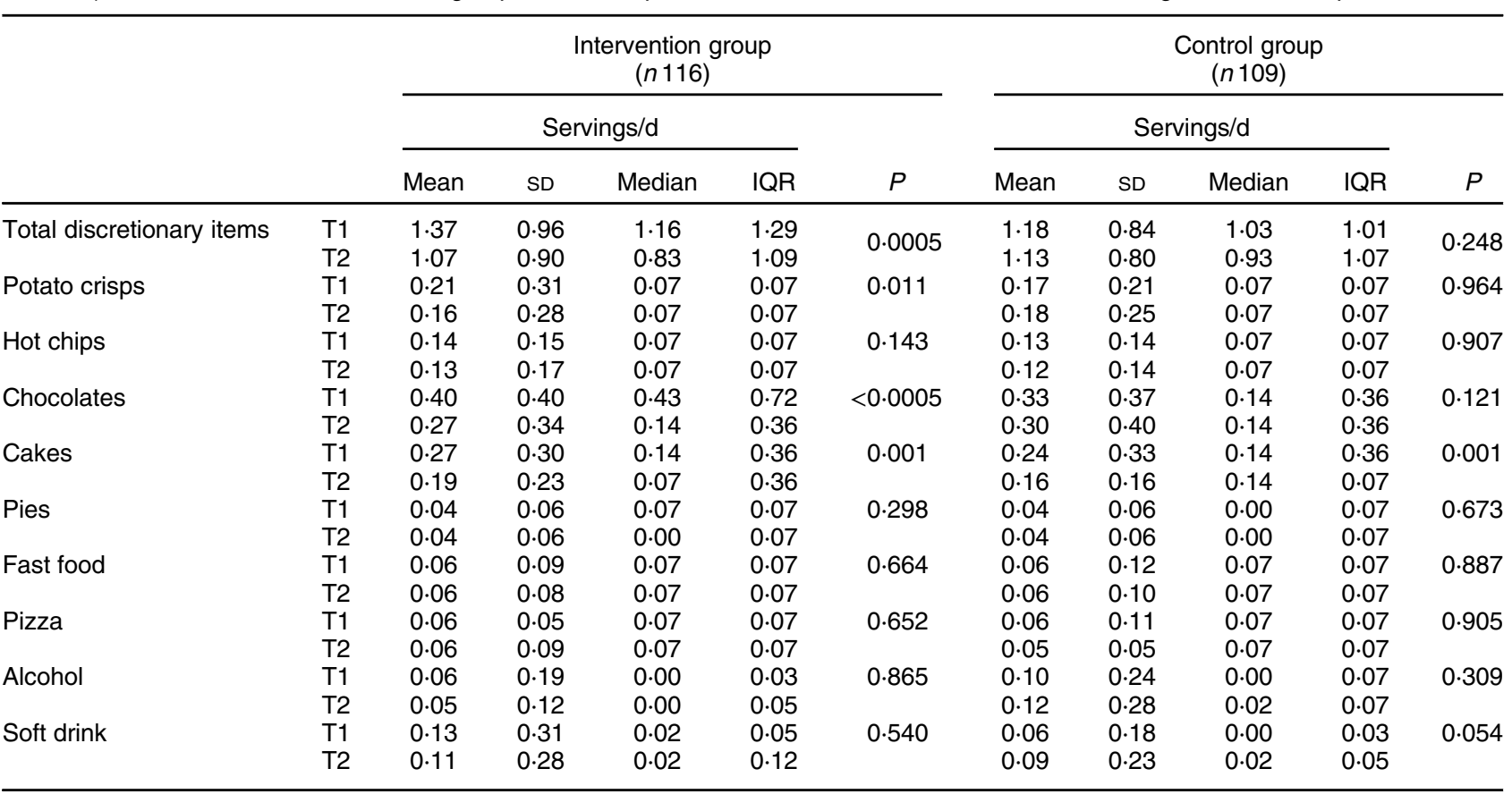

IQR, interquartile range.

(catchment area, age, country of birth, marital status, highest attained level of education, smoking status, children and BMI). The natural exponentiation of this coefficient equals 0.82 (95\% CI 0.69, 0.99), indicating that the intervention group had an approximately $18 \%$ lower median for discretionary servings at T2, compared with the control group.

\section{Mediator analysis}

Four out of the eleven potential mediator variables were found to be associated with the outcome, independent of intervention group, including food tastes/preferences ('I like to drink water'; $b=0.31,95 \%$ CI $0 \cdot 11,0.51$; $P=0.003$ ), outcome expectancies ('When food shopping how much do you consider your own health'; $b=-0 \cdot 22$, 
Table 4 Results of mediator analyses in the ShopSmart randomised controlled trial $(n 225)$

\begin{tabular}{|c|c|c|c|c|c|c|c|c|c|c|c|}
\hline \multirow[b]{2}{*}{ Mediator at T2 } & \multicolumn{3}{|c|}{$\mathrm{IV} \rightarrow \mathrm{M}$} & \multicolumn{3}{|c|}{$M \rightarrow D V$} & \multicolumn{3}{|c|}{$\begin{array}{l}\text { Direct effect } \\
\text { IV } \rightarrow \text { DV }\end{array}$} & \multicolumn{2}{|c|}{$\begin{array}{l}\text { Indirect effect } \\
\mathrm{IV} \rightarrow \mathrm{M} \rightarrow \mathrm{DV}\end{array}$} \\
\hline & $a$ & $95 \% \mathrm{Cl}$ & $P$ & $b$ & $95 \% \mathrm{Cl}$ & $P$ & $c^{\prime}$ & $95 \% \mathrm{Cl}$ & $P$ & $a \times b$ & $95 \% \mathrm{Cl}$ \\
\hline $\begin{array}{l}\text { I like the taste of full- } \\
\text { calorie soft drinks too } \\
\text { much to cut down on } \\
\text { drinking these }\end{array}$ & 0.06 & $-0.13,0.24$ & 0.56 & 0.03 & $-0 \cdot 11,0 \cdot 17$ & 0.67 & $-0 \cdot 19$ & $-0.38,-0.00$ & 0.048 & 0.00 & $-0.01,0.02$ \\
\hline I like to drink water & 0.01 & $-0.11,0.14$ & $0 \cdot 81$ & 0.31 & $0.11,0.51$ & 0.003 & -0.19 & $-0.37,-0.01$ & 0.04 & 0.00 & $-0.04,0.05$ \\
\hline $\begin{array}{l}\text { I feel confident that I can } \\
\text { eat fruit or vegetables } \\
\text { as snacks }\end{array}$ & -0.08 & $-0.22,0.06$ & 0.28 & 0.02 & $-0.16,0.21$ & 0.81 & -0.19 & $-0.38,-0.00$ & 0.049 & -0.00 & $-0.02,0.02$ \\
\hline $\begin{array}{l}\text { When food shopping } \\
\text { how much do you } \\
\text { consider your own } \\
\text { health }\end{array}$ & -0.12 & $-0.29,0.05$ & $0 \cdot 16$ & -0.22 & $-0.38,0.07$ & 0.004 & -0.21 & $-0.40,-0.03$ & 0.03 & 0.03 & $-0.01,0.08$ \\
\hline $\begin{array}{l}\text { How confident do you } \\
\text { feel about preparing } \\
\text { and cooking fruit and } \\
\text { vegetables that you } \\
\text { have not cooked with } \\
\text { before }\end{array}$ & $-0 \cdot 25$ & $-0.63,0.14$ & $0 \cdot 21$ & $0 \cdot 11$ & $0.04,0.17$ & 0.002 & $-0 \cdot 16$ & $-0.34,0.03$ & $0 \cdot 10$ & -0.03 & $-0.08,0.01$ \\
\hline $\begin{array}{l}\text { I feel that I have enough } \\
\text { knowledge about how } \\
\text { to prepare/cook } \\
\text { vegetables }\end{array}$ & -0.13 & $-0.28,0.02$ & $0 \cdot 10$ & 0.02 & $-0 \cdot 14,0 \cdot 19$ & 0.78 & $-0 \cdot 18$ & $-0.37,0.01$ & 0.06 & -0.00 & $-0.26,0.02$ \\
\hline $\begin{array}{l}\text { I feel that vegetables are } \\
\text { time-consuming to } \\
\text { prepare }\end{array}$ & 0.03 & $-0 \cdot 15,0.21$ & 0.75 & $-0 \cdot 22$ & $-0.36,-0.09$ & 0.01 & $-0 \cdot 17$ & $-0.35,0.02$ & 0.07 & -0.01 & $-0.06,0.04$ \\
\hline $\begin{array}{l}\text { I feel that fruit is too } \\
\text { expensive }\end{array}$ & -0.02 & $-0.20,0.17$ & 0.87 & -0.03 & $-0 \cdot 16,0 \cdot 11$ & $0 \cdot 70$ & -0.20 & $-0.39,-0.01$ & 0.04 & 0.00 & $-0.01,0.01$ \\
\hline $\begin{array}{l}\text { I feel that vegetables are } \\
\text { too expensive }\end{array}$ & 0.04 & $-0 \cdot 14,0.24$ & 0.61 & -0.00 & $-0 \cdot 14,0 \cdot 13$ & 0.95 & $-0 \cdot 18$ & $-0.37,0.01$ & 0.06 & 0.00 & $-0.02,0.01$ \\
\hline $\begin{array}{l}\text { I feel that fruit is not } \\
\text { always available }\end{array}$ & -0.05 & $-0.27,0.16$ & 0.61 & -0.08 & $-0.20,0.04$ & $0 \cdot 20$ & $-0 \cdot 18$ & $-0.37,0.01$ & 0.06 & 0.00 & $-0.02,0.03$ \\
\hline $\begin{array}{l}\text { I feel that vegetables are } \\
\text { not always available }\end{array}$ & -0.12 & $-0.32,0.92$ & 0.27 & -0.11 & $-0.23,0.01$ & 0.07 & $-0 \cdot 19$ & $-0.38,-0.01$ & 0.04 & 0.01 & $-0.01,0.05$ \\
\hline
\end{tabular}

T2, intervention completion (6 months post-baseline); IV, independent variable/exposure/intervention; M, mediator; DV, dependent variable/outcome/discretionary foods. As seen in Fig. 2, a represents the relationship of IV to $M$, and $b$ represents the relationship of $M$ to DV adjusting for IV. There is a direct effect $\left(c^{\prime}\right)$ relating IV to DV adjusting for $\mathrm{M}$, and a mediated effect where IV indirectly affects DV through $M$.

Models controlled for baseline levels of the outcome and baseline levels of the mediator, as well as the following covariates: catchment area, age, country of birth, marital status, highest attained level of education, smoking status, children and BMI.

$95 \%$ CI $-0 \cdot 38,0 \cdot 07 ; P=0 \cdot 004$ ), self-efficacy ('How confident do you feel about preparing and cooking fruit and vegetables that you have not cooked with before'; $b=0 \cdot 11$, $95 \%$ CI $0.04,0 \cdot 17 ; P=0.002$ ) and time constraints ('I feel that vegetables are time-consuming to prepare'; $b=-0.22$, $95 \%$ CI $-0.36,-0.09 ; P=0.011)$. However, there was no evidence that they mediated intervention effects $(P>0.05)$. This is largely explained by the fact that there were no intervention effects observed for any of the mediators selected (Table 4).

\section{Discussion}

The present study demonstrated that an intervention focused on promoting fruit and vegetables among socioeconomically disadvantaged participants was effective in reducing intakes of unhealthy discretionary items, even in the absence of a specific focus on limiting such foods. On average, those in the intervention group reduced their discretionary food intake by 0.3 servings/d at intervention completion, which is equivalent to approximately $180 \mathrm{~kJ} / \mathrm{d}$. This was primarily due to a decline in consumption of potato crisps, chocolates and cakes. Although this reduction in energy intake may appear small, other studies have shown the importance of similar daily declines ${ }^{(32)}$. For example, Hall et al. reported that every change in energy intake of $100 \mathrm{~kJ} / \mathrm{d}$ will lead to an eventual body weight change of about $1 \mathrm{~kg}^{(33)}$. Hence, our findings are of likely clinical significance when considering that modest weight losses of 5 to $10 \%$ of body weight can contribute to important health benefits including improved glucose tolerance, hyperlipidaemia and blood pressure in overweight and obese adults ${ }^{(34)}$. Moreover, unhealthy dietary patterns have been associated with increased risk of chronic diseases, including CHD, type 2 diabetes, metabolic syndrome, some types of cancer ${ }^{(35)}$ and depression ${ }^{(36)}$, and lower intakes of essential nutrients ${ }^{(37)}$. Thus, even small reductions in discretionary food servings is likely to be associated with a number of health benefits. 
Food choice is a complex behaviour as demonstrated by the consistently poor-quality diets of the nation ${ }^{(3)}$. The positive findings of the present study provide us with an alternative perspective on successful programme design, such as stealth interventions ${ }^{(13)}$ where emphasis is placed on incentives for the process of behaviour change rather than outcomes. For example, the ShopSmart study promoted fruit and vegetable consumption by encouraging self-efficacy (e.g. label reading, meal planning, cooking, budgeting, etc.), meal enjoyment, social interaction and goal setting, with minimal focus on restricting unhealthy foods ${ }^{(21)}$. These design features make the behaviour change process rewarding and desirable rather than a sacrifice or burden, as 'diets' are often perceived to be $\mathrm{b}^{(13)}$.

One limitation of the present study was the use of selfreported FFQ items. These items have been widely used in other population-based studies but were not validated as a complete FFQ against other dietary assessment tools. This may have resulted in socially desirable under-reporting of discretionary food intake. However, given the intervention did not focus explicitly on reducing discretionary foods, it seems unlikely that this completely accounts for the reduction in reported intakes observed in the intervention group compared with the control group. The present study failed to identify mediators on the explanatory pathway linking the intervention to a reduction in discretionary food consumption. Given the intervention was focused on fruit and vegetables, it is possible that the ShopSmart survey did not include measures of mediators relating to the intervention's effect on discretionary foods. Additionally, some mediator measures lacked variation in responses (e.g. included only three response options), which may have reduced the ability to identify mediating effects. Moreover, due to the half-longitudinal analysis performed, the examined relationships between the mediators and outcome were actually cross-sectional. Purposefully designed measures focused on discretionary foods (e.g. confidence for, or environmental barriers to, reducing discretionary foods) may have helped highlight the important pathways. Future studies may also benefit from including additional measures of potential mediating factors such as those relating to household values or social factors, for example relationships of individuals that can constrain or facilitate food choice decisions. Early family cuisine, upbringing and family dynamics can result in the development of food roles and eating identities that lead to persistent patterns of food choices ${ }^{(38)}$.

Strengths of the present study include the randomised controlled trial design and low attrition rates, which demonstrates that the ShopSmart intervention effectively attracted and retained women of low socio-economic position, who are a commonly difficult group to engage ${ }^{(39)}$. Robust analyses of mediators were performed and a range of covariates was included in both the mediator model and linear regression analysis.
Although specific mediators were not identified, researchers and public health professionals should continue searching for mechanisms by which interventions have an effect to guide future programme design. A better understanding of why some interventions/programmes do or do not work will help to inform future programme decision making. Importantly, the present study is one of few to demonstrate that an intervention focused on promoting fruit and vegetables was effective in reducing intakes of discretionary items, even in the absence of a specific focus on limiting such foods. Hence, programmes such as stealth interventions ${ }^{(13)}$, which emphasise incentives for the process of behaviour change rather than outcomes, may encompass the necessary features for achieving programme success. Maintaining a holistic view of food choice decisions and food behaviours is likely essential ${ }^{(40)}$. Food behaviours are complex and cannot be detached or extracted from many other aspects of people's lives, in addition to structure (e.g. social institutions and other environments) and individual agency. Without considering all these aspects, future programmes are likely to be insufficient to produce the desired outcomes.

\section{Acknowledgements}

Acknowledgements: Coles supermarkets and the National Heart Foundation of Australia provided in-kind support (e.g. access to FlyBuys database for recruitment; assistance with fruit and vegetable promotion resources). Financial support: The ShopSmart 4 Health study was supported by the Australian Research Council's Linkage Projects funding scheme (project LP0990129). S.A.M. is supported by a National Health and Medical Research Council Career Development Fellowship Level 2 (ID1104636) and was previously supported by an Australian Research Council Future Fellowship (2011-2015, FT100100581). The funding bodies had no role in the design, implementation, analysis or interpretation of the study and the article contents do not reflect the views of the funding bodies. Conflict of interest: None. Authorship: K.B. and D.C. designed the original ShopSmart research; K.B., S.A.M., Ha N.D. Le and D.C. developed measures and conducted the original ShopSmart research. For this study specifically, R.S.O. and K.B. designed and conducted the research; R.S.O. and G.A. designed the analytical plan, analysed the data and performed statistical analyses; and all authors drafted the manuscript, contributed to revising the manuscript, interpreted the data, and read and approved the final manuscript. Ethics of human subject participation: The ShopSmart 4 Health trial was registered at www.isrctn.com as ISRCTN48771770. This study was conducted according to the guidelines laid down in the Declaration of Helsinki and all procedures involving human subjects were approved by the Deakin University Faculty of Health Human Ethics Advisory Group (HEAG-H 188/09). Written informed consent was obtained from all participants. 


\section{References}

1. World Health Organization (2011) Global Status Report on Noncommunicable Diseases: 2010. Geneva: WHO.

2. Di Cesare M, Khang YH, Asaria P et al. (2013) Noncommunicable diseases 3: inequalities in non-communicable diseases and effective responses. Lancet 381, 585-597.

3. Livingstone KM \& McNaughton SA (2018) Association between diet quality, dietary patterns and cardiometabolic health in Australian adults: a cross-sectional study. Nutr J 12, 1-19.

4. National Cancer Institute, Division of Cancer Control \& Population Sciences (2015) Epidemiology and Genomics Research Program. Usual dietary intakes: food intakes, US population, 2007-10. http://epi.grants.cancer.gov/diet/ usualintakes/pop/2007-10/ (accessed September 2019).

5. Australian Bureau of Statistics (2014) 4364.0.55.007 - Australian Health Survey: Nutrition First Results - Foods and Nutrients, 2011-12. Discretionary foods. https://www. abs.gov.au/ausstats/abs@.nsf/Lookup/by\%20Subject/4364. 0.55.007 2011-12 Main\%20Features Discretionary\%20foo ds 700 (accessed July 2018).

6. National Health and Medical Research Council (2013) Healthy Eating for Adults: Eat for Health and Wellbeing. https://www.eatforhealth.gov.au/sites/default/files/content/ The\%20Guidelines/n55g_adult_brochure.pdf (accessed September 2019).

7. Pomerleau J, Lock K, Knai C et al. (2005) Interventions designed to increase adult fruit and vegetable intake can be effective: a systematic review of the literature. $J$ Nutr 135, 2486-2495.

8. Haire-Joshu D, Brownson RC, Nanney MS et al. (2003) Improving dietary behavior in African Americans: the Parents As Teachers High 5, Low Fat Program. Prev Med 36, 684-691.

9. Havas S, Anliker J, Damron D et al. (1998) Final results of the Maryland WIC 5-A-Day Promotion Program. Am J Public Health 88, 1161-1167.

10. Havas S, Anliker J, Greenberg D et al. (2003) Final results of the Maryland WIC food for life program. Prev Med 37, 406-416.

11. Langenberg P, Ballesteros M, Feldman R et al. (2000) Psychosocial factors and intervention-associated changes in those factors as correlates of change in fruit and vegetable consumption in the Maryland WIC 5 a Day Promotion Program. Ann Behav Med 22, 307-315.

12. Tredici D, Joy AB, Omelich CL et al. (1998) Evaluation study of the California Expanded Food and Nutrition Education Program: 24-hour food recall data. J Am Diet Assoc 88, 185-190.

13. Robinson TN (2010) Stealth interventions for obesity prevention and control: motivating behavior change. In Obesity Prevention: The Role of Brain and Society on Individual Behavior, pp. 319-327 [L Dube, A Bechara, A Dagher et al., editors]. Amsterdam/Boston, MA: Academic Press.

14. Mann T, Tomiyama AJ, Westling E et al. (2007) Medicare's search for effective obesity treatments: diets are not the answer. Am Psychol 62, 220-233.

15. Bandura A (1989) Human agency in social cognitive theory. Am Psychol 44, 1175-1184.

16. Eertmans A, Baeyens F \& Van den Bergh O (2001) Food likes and their relative importance in human eating behaviour: review and preliminary suggestions for health promotion. Health Educ Res 16, 443-456.

17. Newman LP, Bolhuis DP, Torres SJ et al. (2016) Dietary fat restriction increases fat taste sensitivity in people with obesity. Obesity (Silver Spring) 24, 328-334.
18. Snyder LB (2007) Health communication campaigns and their impact on behavior. J Nutr Educ Behav 39, 2 Suppl., S32-S40.

19. Ball K, McNaughton SA, Le HN et al. (2016) ShopSmart 4 Health: results of a randomized controlled trial of a behavioral intervention promoting fruit and vegetable consumption among socioeconomically disadvantaged women. Am J Clin Nutr 104, 436-445.

20. Bandura A (2004) Health promotion by social cognitive means. Health Educ Behav 31, 143-164.

21. Ball K, McNaughton SA, Le H et al. (2013) ShopSmart 4 Health - protocol of a skills-based randomised controlled trial promoting fruit and vegetable consumption among socioeconomically disadvantaged women. BMC Publich Health 13, 466.

22. Lake A, McNaughton SA, Le H et al. (2006) Food shopping and preparation among the 30-somethings: whose job is it? (The ASH30 study). Br Food J 108, 475-486.

23. Australian Bureau of Statistics (1998) National Nutrition Survey: User's Guide, 1995. Canberra, ACT: Commonwealth of Australia.

24. Ball K, Cleland V, Salmon J et al. (2013) Cohort profile: the resilience for eating and activity despite inequality (READI) study. Int J Epidemiol 42, 1629-1639.

25. McNaughton SA, Crawford D, Ball K et al. (2012) Understanding determinants of nutrition, physical activity and quality of life among older adults: the Wellbeing, Eating and Exercise for a Long Life (WELL) study. Health Qual Life Outcomes 10, 109.

26. National Health and Medical Research Council (2009) Australian guidelines to reduce health risks from drinking alcohol. https://www.nhmrc.gov.au/about-us/publications/ australian-guidelines-reduce-health-risks-drinking-alcohol (accessed September 2019).

27. Caspi CE, Sorensen G, Subramanian SV et al. (2012) The local food environment and diet: a systematic review. Health Place 18, 1172-1187.

28. Sleddens EFC, Kroeze W, Kohl LF et al. (2015) Correlates of dietary behaviour in adults: an umbrella review. Nutr Rev $\mathbf{7 3}$, 477-499.

29. Brug J (2008) Determinants of healthy eating: motivation, abilities and environmental opportunities. Fam Pract 25, Suppl. 1, i50-i55.

30. Cole DA \& Maxwell SE (2003) Testing mediational models with longitudinal data: questions and tips in the use of structural equation modeling. J Abnorm Psychol 112, 558-577.

31. Hayes AF (2012) PROCESS: a versatile computational tool for observed variable mediation, moderation, and conditional process modeling. http://www.afhayes.com/public/ process2012.pdf (accessed September 2019).

32. Hill JO (2009) Can a small-changes approach help address the obesity epidemic? A report of the Joint Task Force of the American Society for Nutrition, Institute of Food Technologists, and International Food Information Council. Am J Clin Nutr 89, 477-484.

33. Hall KD, Sacks G, Chandramohan D et al. (2011) Quantification of the effect of energy imbalance on bodyweight. Lancet 378, 826-837.

34. National Institute of Health (1998) National Heart, Lung, and Blood Institute Clinical guidelines on the identification, evaluation, and treatment of overweight and obesity in adults: the evidence report. Obes Res 6, Suppl. 2, 51S-209S.

35. Tyrovolas S \& Panagiotakos DB (2010) The role of Mediterranean type of diet on the development of cancer and cardiovascular disease, in the elderly: a systematic review. Maturitas 65, 122-130. 
36. Jacka F, O'Neil A, Opie R et al. (2017) A randomised controlled trial of dietary improvement for adults with major depression (the 'SMILES' trial). BMC Med 15, 23.

37. Johnson RK, Appel LJ, Brands M et al. (2009) Dietary sugars intake and cardiovascular health: a scientific statement from the American Heart Association. Circulation 120, 1011-1120.

38. Sobal J \& Bisogni CA (2009) Constructing food choice decisions. Ann Behav Med 38, Suppl. 1, S37-S46.
39. Bull ER, Dombrowski SU, McCleary N et al. (2014) Are interventions for low-income groups effective in changing healthy eating, physical activity and smoking behaviours? A systematic review and meta-analysis. BMJ Open 4, e006046.

40. Sallis JF, Owen N \& Fisher EB (2008) Ecological models of health behaviour. In Health Behaviour and Health Education: Theory, Research, and Practice, pp. 465-485 [K Glanz, BK Rimer and K Viswanath, editors]. San Francisco, CA: Jossey-Bass. 